\title{
"Mind the gap": reflections of an American health maintenance organisation doctor on the new NHS
}

\author{
James E Sabin
}

As I prepared to return to the United States after a three month sabbatical to study ethical dimensions of the NHS changes since Working for Patients, an unlikely phrase from the London Underground kept presenting itself - "Mind the gap!"

I eventually discerned four "gaps" that capture the lessons I would take back to the United States and the suggestions I wanted to leave in the United Kingdom. Firstly, a gap between the health care you want and the money you are willing to spend. Secondly, a gap in communication between doctors and patients about the economics of the NHS. Thirdly, a gap between two cultures-described by the new secretary of state for health, Virginia Bottomley, as "the world(s) of medicine and management." Finally, a gap in medical ethics between old precepts and new circumstances. If you address these gaps effectively the NHS will be a model for the twenty first century. If you do not you will undermine what many of my interviewees called a "national treasure."

Gap between what you want and what you will pay for

Even though the United States spends $270 \%$ more per capita than the United Kingdom on health care, American doctors, like their British counterparts, complain about underfunding. What distinguishes the two countries is not the perception of a funding gap, but the profoundly different values each uses to determine how much to spend in the first place. Where the United States is driven by the rights of individuals, the United Kingdom has emphasised the needs of communities.

During my visit I encountered tremendous interest in the Oregon experiment, but the experiment in the United Kingdom is far more radical. Oregon is preparing to purchase health care for a portion of the population in a single state. In the United Kingdom every district health authority has been purchasing health care for its entire population since 1 April 1991. I do not believe, however, that politicians or the public yet realise how revolutionary and explosive the bureaucratic-sounding "separation of purchaser from provider" is likely to be.

If I were forced to identify the most demanding ethical task in the NHS at present I would choose purchasing. I admire but do not envy the leaders of the South East London Commissioning Agency (representing the Camberwell, Lewisham and North Southwark, and West Lambeth District Health Authorities), who so boldly accept what Americans call the "hot seat":

[We will] target our resources, following an evaluation of health care needs, so as to gain the greatest improvement in our population's health ... We will aim for a comprehensive service to achieve genuine health gains, but as we have limited resources we will be explicit about those needs which can be met and those which cannot. ${ }^{2}$

Their intentions are breathtaking. Public officials prefer to waffle about hard choices, but there is no waffling here. The agency resoundingly endorses utilitarian values, with no mention of individual rights. Success will be measured by improved community health. The agency makes no promises to individuals. It boldly commits itself to telling the truth when it does not provide for a need, rather than doing what I have often observed in the United States-disingenuously changing terms and redefining the unmet "need" as a "preference" or "demand."

All the purchasers I talked with, however, worry that although they have statutory authority to purchase for their districts, they do not have real legitimacy in the eyes of the district population, which is barely aware of the whole idea of purchasing. As I work at a Health Maintenance Organisation I find that comparing district health authorities with health maintenance organisations helps to clarify the issue of legitimacy. Like district health authorities, health maintenance organisations provide all the care for $15 \%$ of the American population on a prepaid basis. Unlike district health authorities, members of health maintenance organisations are not automatically "enrolled" according to where they live - they decide each year whether to belong to them. Their enrolment confers legitimacy on the organisation. A dissatisfied member can "fire" the health maintenance organisation and join another programme. On average $5-10 \%$ of members do this each year.

District health authority purchasers are trying to cultivate legitimacy by doing surveys, creating forms of dialogue with their communities, and deepening their ties with general practitioners, but their position is highly vulnerable. At the same time that the South East London Commissioning Agency defines its mission as purchasing for the community by utilitarian values, the patient's charter invites highly individual expectations by using American style language of rights - "every citizen has [a right] to receive health care on the basis of clinical need." ${ }^{\prime}$ I fear that entities like the commission may not be able to sustain their utilitarian ethic when they find-as ultimately they must - that they cannot meet some of the real needs of real people, and shrouds begin to wave.

The highly exposed position of the district health authority as purchaser leads me to make three predictions. Firstly, central government will rapidly come under tremendous funding pressure from district managers. One purchaser told me that while "parliament may have hoped that establishing districts as purchasers would build a moat between the national government and resource pressure, they are living in cloud cuckoo land if they think the changes will really insulate them." Secondly, well before the debate between implicit and explicit rationing, which was launched in this journal in January 1991 is settled, the public will realise that rationing is a fact of life in the districts and you will enter a period of heated moral and political controversy. ${ }^{4}$ Finally, although citizens effectively have no choice about their districts, which creates a severe problem of legitimacy, they can "hire and fire" their general practitioner. I predict that fundholding general practitioners will join with hospital trusts to form new entities providing primary, consultant, and hospital care, much as American 


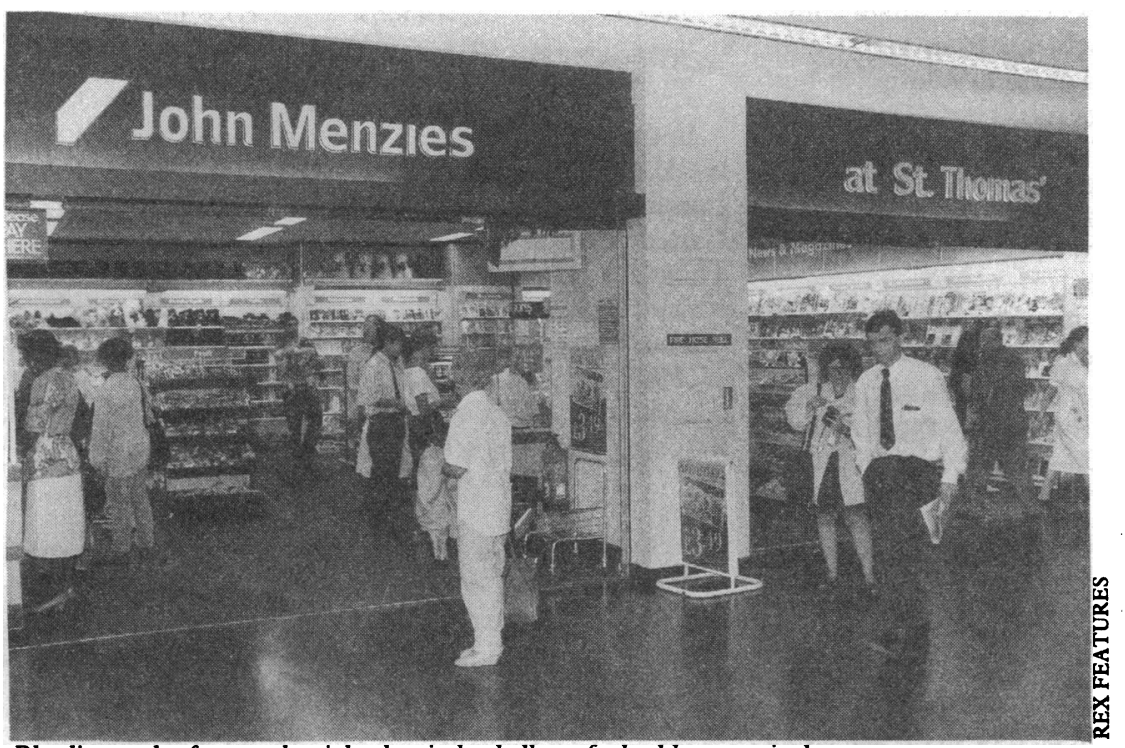

Blending market forces and social values is the challenge for health systems in the next century

health maintenance organisations do. Like district health authorities these entities will have to ration, but they will diminish the problem of legitimacy by giving the citizen a choice regarding membership, the way American health maintenance organisations do.

\section{Communication gap between doctors and patients}

A general practitioner whom I asked about his experiences discussing resource allocation with patients told me the following story.

Shortly after I began to practise a patient consulted me about a cough. She wanted an antibiotic, which wasn't clinically indicated. Instead of just saying that I would prescribe what she needed and that she didn't need an antibiotic, which is the kind of thing I usually say, I said something like- "we shouldn't waste money on an antibiotic when you don't need it so we will have resources available when you do." All she heard was the word "money." She went home all worked up, and the next thing I knew the cough had turned into pneumonia and she really did need the antibiotic!

Many doctors told me anecdotes of this kindgenerally humorous. I came to regard these as "cautionary fables," designed to warn that discussing money with patients is dangerous. Others told me how disturbed and even angry they were on the relatively rare occasions when patients asked them if cost considerations had influenced their thinking. Doctors seem to feel stronger taboos against discussing money than sex.

Patients seemed much readier to acknowledge resource limitations and talk about them than their doctors were. Sitting with general practitioners in their surgeries, I noted how regularly patients moved rapidly into the office and presented a focused agenda, recognising and accepting the fact that the doctor had little time and many patients. I was able to ask patients about their behaviour, and I satisfied myself that they acted as they did from a realistic recognition of the limits on collective resources, not low self esteem or inability to ask for anything for themselves.

As a psychiatrist I was especially moved by a story told by the father of a 26 year old man with schizophrenia, which became emblematic for me of how much the British view health care as a community resource rather than an individual right.

Robin had been getting increasingly psychotic, deluded, and agitated during the previous few weeks. He has been ill for five years, since his first attack as an undergraduate at
Cambridge. He had always lived with us since then, and we recognised the signs that he was going downhill fast. But our general practitioner told us there was a waiting list, and the psychiatrist said he was not ill enough yet. Over Christmas, he was driving us up the wall. He was very trying. Then on New Year's Day, he got really psychotic. I lost my temper and forced the system. I physically ejected my own son from the house and told him to go to the police. I knew they could make the hospital admit him.... I feel terribly guilty about the whole thing, having to use coercion, putting the police and the hospital on the spot, but we were desperate. I may have been doing a more deserving patient out of a bed. One should not have to descend into this wheeling and dealing. ${ }^{5}$

I am convinced that users of the NHS, like Robin's father, are ready to collaborate with their doctors in seeking to manage limited resources fairly but that doctors in the United Kingdom as in the United States are just beginning to learn how to join with them. Thirty years ago doctors believed it was harmful to discuss terminal illness and told cautionary tales about patients who gave up hope or committed suicide on receiving a diagnosis of cancer. We have since learnt how to make bad news part of good care, and I anticipate that we will have to do the same with the new economic factors that impinge on medical practice.

\section{Gap between medical and managerial cultures}

For an American doctor, Rudolf Klein's analysis of the "radical transformation" that Working for Patients engendered in the NHS provides an experience of déjà vu. According to Klein, the 1948 "concordat" between the state and medical profession, which gave doctors a degree of autonomy and government a level of budgetary control well beyond anything we have ever had in the United States, is now undergoing fundamental change. ${ }^{6}$ The terms Klein uses to describe the transition from an era of professional "status," when the state trusted doctors to govern themselves in accord with public interest, to a relationship of "contract," in which the medical profession becomes accountable to managers, could easily come from an American medical journal of 10 years ago.

As a foreigner I was allowed to enter rival medical and managerial camps much as the Red Cross can do in battle zones. One highly committed doctor described management as "the syphilis of the NHS." An equally committed manager said that "before the reforms the NHS was run by consultants who in the past would have been bucanneers on the high seas." Yet despite the profound distrust between medicine and management virtually every encounter also gave evidence of shared ideals.

The special representative meeting of the BMA in March of this year showed a profession in turmoil and some disarray. The group enthusiastically endorsed motions that affirmed utterly incompatible positions. Moments after the representatives condemned "fixed budgets" and any restriction on "freedom of choice for patients and their doctors," they agreed-by a similar majority - "that rationing of health care is inevitable." Surely rationing will require fixed budgets and restrictions of choice!

Gatherings of American doctors show similar fiery rhetoric, inconsistent positions, and volatile moods. Rapid change elicits symptoms of adolescence on both sides of the Atlantic. These growing pains are probably healthy signs of our profession struggling to adapt. I was much more alarmed by the degree of hostility within the BMA between those who believe the NHS changes must be fought without compromise and those who want to get on with the task of caring for patients and making the changes work as well as possible. A visitor can only hope that you will be more successful 
than we in the United States have been at distinguishing principles that should be fought for from habits and vested interests that may be painful to relinquish but do not reflect the ethical core of medicine.

Virginia Bottomley wants "the world(s) of medicine and management to coexist comfortably." My observations suggest that your effort to embrace both "traditional collective responsibilities" and "the new consumerism" will create too much tension for comfort. " "Effective collaboration with tolerable levels of conflict" would be a more realistic objective for Mrs Bottomley. The NHS of the future will need managerial as well as medical virtues. To bridge the gap between the two cultures, however, you will need imaginative leadership from the secretary of state for health, the $\mathrm{BMA}$, and the royal colleges.

\section{Gap between traditional medical ethics and the new NHS}

Doctors in both the United States and the United Kingdom are struggling to develop ethical precepts for circumstances in which - to use Marshall Marinker's terms - they face the "[daunting] prospect of being at once the advocate for the individual patient and the arbiter of distributive justice for the practice population." " Despite the power of the taboo against discussing rationing explicitly with patients I believe that you in the United Kingdom have progressed further than we have in the United States.

Doctors in the United States still ask if it is unethical to consider cost in making treatment recommendations. The American Medical Association's code of ethics provides no guidance. The BMA code does: "It is the doctor's ethical duty to use the most economic and efficacious treatment available." At the special representative meeting of the BMA delegates presented 27 separate motions affirming the need for rationing. The question for you is not whether to set priorities and ration but how to do it.

The best opportunity to develop the new ethics may be in teaching medical students and young doctors. Here are vignettes from three superb small group discussions in the general practice clerkship at Guy's and St Thomas's Hospitals. They illustrate how students and faculty can explore how to balance fiduciary attention to patients and stewardship of public resources.

The general practitioner advised a man with cellulitis to enter the hospital for intravenous antibiotic treatment, but the patient was adamant in refusing. The students debated "beneficence" (caring for his cellulitis) versus "autonomy" (respecting his wish to remain at home). When I described the use of home intravenous antibiotic treatment at my health maintenance organisation, the students recognised that it might be possible to treat the cellulitis (beneficence), respect the patient's wish to be at home (autonomy), while at the same time reducing the cost of the treatment (justice) - a superior clinical and ethical outcome.

The man with a cough secondary to lung cancer wanted an antibiotic which the general practitioner thought was not clinically indicated. Half of the students favoured prescribing it-largely to strengthen the doctor-patient relationship. The other half thought this would be a bad precedent and opposed prescribing the antibiotic. I noted that no one had mentioned cost and asked if it would matter whether the antibiotic cost $£ 5$ or $£ 100$. In the discussion that followed one student said, - "I guess we have to manage medicine in a businesslike way... what we spend in one area could have helped people somewhere else."

A young couple asked the general practitioner for a chromosome test to establish the paternity of their baby. The students discussed the complex issues involved in counselling the couple and deciding how to respond to the request. When I asked them, "if you decide it is clinically the right thing to do, is it the kind of service the NHS funds should pay for?" they moved into a vigorous debate about the goals of health care and need to set priorities.

In the next several years medical schools throughout the United Kingdom, like St Bartholomew's and the London Hospital Medical School, ${ }^{10}$ Oxford, and the United Medical and Dental Schools of Guy's and St Thomas's Hospitals, will be experimenting with new ethics curricula. At the same time the Central Ethical Committee of the BMA will be writing the next edition of Philosophy and Practice of Medical Ethics. My colleagues and I from the United States will be avidly watching your progress.

\section{Conclusion}

We Americans desperately need to learn how to extend good health care to our entire population and at the same time set limits on spending. Developments in the United Kingdom could teach us a great deal. Until now, however, Americans have used the notorious NHS waiting lists, and our suspicion that the United Kingdom places substantially less value on the strong forms of doctor-patient partnership and informed consent that we cherish, to discount the lessons of your impressive accomplishments."

But we will not be able to avoid learning from the NHS much longer. As Rudolf Klein has shown, our two systems are converging..$^{12}$ The United States may procrastinate, but we will inevitably provide health care to all our citizens, and the recent election ensures that the NHS will continue to develop an "internal market."

The medical profession in the United Kingdom has been traumatised and is now in a zone of choice. Resisting the changes engendered by Working for Patients might seem to be the simpler course, but it will not succeed. For better or worse, all first world economies are currently using market mechanisms as a major form of control. The effort in the United Kingdom to blend the social values of the NHS with market structures could create a prototype for the next century. Success, however, will require developing skill at district level at involving the public in setting priorities and rationing, improving doctors' skills at collaborating with patients to manage resources, creating rapprochement between medical and managerial cultures, and adopting new ethical precepts for the new circumstances. If you are able to mind these gaps your model will be one from which other countries, especially the United States, can learn crucial lessons.

JES was a visiting fellow at the Centre of Medical Law and Ethics, King's College, University of London from February to April 1992.

1 O'Sullivan J. Bottomley would shut uneconomic NHS hospitals. Independent 1992 Apr 17:7.

2 South East London Commissioning Agency. Aiming for the best of health. London: SELCA, 1991:4,9.

3 Department of Health. The patient's charter. London: HMSO 1991.

4 Smith R. Rationing: the search for sunlight. BMF 1991;303:1561-2.

5 O'Sullivan J. Hospital crisis breaks a family. Independent $1992 \mathrm{Mar}$ 8:9.

6 Klein R. From status to contract: the transformation of the British medical profession. In: L'Etang H, ed. Health care provision under financial constraint: a decade of change. London: Royal Society of Medicine, 1990:127-34.

7 Klein R. The politics of the National Health Service. London: Longman, 1989:197.

8 Marinker M. Changes and developments in primary care. In: L'Etang $H$, ed. Health care provision under financial constraint: a decade of change. London: Royal Society of Medicine, 1990:141-8.

9 British Medical Association. Philosophy and practice of medical ethics. London: BMA, 1988:72.

10 Doyal L. Teaching ethics at Bart's and The London. Bulletin of Medical Ethics 1991; September: 19-22.

11 Schwartz R, Grubb A. Why Britain can't afford informed consent. Hasting Center Report 1985;15(August): 19-25.

12 Klein R. The American health care predicament: spending more, feeling worse. BMF 1991;303:259-60.

(Accepted 23 fuly 1992) 